Referencia para citar este artículo: Di Piero, E. (2019). Miradas docentes sobre los jóvenes y las jóvenes como «otros indeseables» en secundarias universitarias en La Plata. Revista Latinoamericana de Ciencias Sociales, Niñez y Juventud, 17(1), 269-283. doi:https://dx.doi.org/10.11600/1692715x.17116

\title{
Miradas docentes sobre los jóvenes y las jóvenes como «otros indeseables» en secundarias universitarias en La Plata*
}

\author{
EMILIA Di PIERo** \\ Profesora-investigadora Universidad Nacional de La Plata, Argentina.
}

\section{Artículo recibido en diciembre 7 de 2016; artículo aceptado en julio 9 de 2018 (Eds.)}

- Resumen (analítico): en este artículo, en el que presentamos conclusiones de una investigación doctoral, nos enfocamos en las miradas de docentes de secundarias universitarias en La Plata (Argentina) acerca de los jóvenes y las jóvenes que las transitan. Se trata de escuelas prestigiosas que modificaron su admisión desde el examen eliminatorio hacia el sorteo durante el retorno de la democracia a Argentina en la década de los ochenta. El enfoque metodológico partió de un estudio de caso múltiple: entre 2012 y 2016 realizamos observaciones, entrevistamos a 13 actores claves y a 67 docentes, analizamos actas del momento de modificación de la admisión e información sociodemográfica de ingresantes. Concluimos que la retórica nostálgica de la educación pasada es atravesada por la añoranza de los «jóvenes de ayer»: en las miradas de los docentes, la «decadencia educativa» se imbrica con el desencanto frente a la juventud actual.

Palabras claves: docente, joven, escuela secundaria, universidad, representaciones (Tesauro de Ciencias Sociales de la Unesco).

\section{Teachers' views of young people as «undesirable others» in university secondary schools in La Plata}

- Abstract (analytical): In this paper we present conclusions from a doctoral research study focusing on the analysis of the views of teachers in two university secondary schools in La Plata (Argentina) of the young people they teach. These are prestigious schools that changed their admissions process from the results-based exam to a public lottery, with the idea of returning to the democratic institutional approaches used in Argentina in the 1980s. The methodological approach started with a multiple case study: between 2012 and 2016 the researcher engaged in observations, interviewed 13 «key» actors and 67 teachers and analysed meeting records related to the change in the admissions process, as well as sociodemographic information of the enrolled students. The author concludes that the rhetoric, tinged with melancholy, for the education processes from the past also includes a longing for the «youth of yesterday». In the views of teachers, this «educational decadence» is affected by their disappointment with today's youth.

Este artículo de investigación científica y tecnológica se basa en la investigación «Justicia, meritocracia e igualitarismo. Procesos de producción y legitimación de desigualdades en escuelas secundarias universitarias en la ciudad de La Plata», realizada entre el $1^{\circ}$ de marzo de 2012 y el 29 de julio de 2016, con financiación del Consejo Nacional de Investigaciones Científicas y Técnicas de Argentina. Número de contrato: 10520160300294CO01. Gran área de conocimiento: Ciencias Sociales. Área de conocimiento: Sociología. Subárea de conocimiento: Ciencias de la Educación.

** Doctora en Ciencias Sociales/Facultad Latinoamericana de Ciencias Sociales, Argentina. Magíster en Ciencias Sociales con Orientación en Educación/Flacso Argentina. Licenciada y profesora en Sociología de la Universidad Nacional de La Plata. Becaria posdoctoral del Consejo Nacional de Investigaciones Científicas y Técnicas con lugar de trabajo en el área de educación de Flacso Argentina. Investigadora y docente de grado y posgrado de la Universidad Nacional de La Plata. Orcid: 0000-0002-1500-7542. Correo electrónico: medipiero@gmail.com 
Key words: Teacher, young, secondary school, university, representations (Unesco Social Science Thesaurus).

\title{
Olhares dos professores sobre os jovens como «outros indesejáveis» em escolas universitárias de ensino médio em La Plata
}

- Resumo (analítico): neste artigo apresentamos resultados de uma pesquisa doutoral enfocando a análise nos olhares dos professores secundários universitários em La Plata (Argentina) sobre a juventude. É um grupo de escolas de prestígio que variaram seu método de admissão do exame de qualificação ao sorteio no contexto do retorno da democracia na Argentina nos anos 80. A abordagem metodológica consistiu num estudo de caso múltiplo: entre 2012 e 2016 fizemos observações, entrevistamos 13 atores chaves e 67 professores, analisamos documentos do momento de modificação de admissão e informações sócio-demográficas dos alunos. Conclui-se que a retórica cheia de nostalgia para a educação do passado é atravessada pelo anseio do «jovem de ontem» aos olhos dos professores, a «decadência educacional» se sobrepõe ao desencanto com as juventudes de hoje.

Palavras-chave: professor, jovem, escola média, universidade, representação (Thesaurus de Ciências Sociais da Unesco).

-1. Introducción. -2. Metodología. -3. Dos escuelas de pregrado. -4. «Por sorteo entra cualquiera» o la añoranza de una juventud meritoria. -5. Visiones adultocéntricas: de la autonomía como exigencia. $\mathbf{- 6}$. Reflexiones finales. -Lista de referencias.

\section{Introducción}

\author{
A simple vista puedes ver \\ como borrachos en la esquina de algún tango \\ a los jóvenes de ayer. \\ Empilchan bien, usan tupé \\ se besan todo el tiempo y lloran el pasado \\ como vieja en matiné.
}

SERÚ GIRÁn, grupo musical argentino

La progresiva ampliación de la escolarización secundaria en Argentina y la extensión de la obligatoriedad para el nivel a partir del año 2006 agudizaron las tensiones en un nivel educativo pensado originalmente para la formación de élites dirigentes. Este artículo es parte de una investigación doctoral en la cual indagamos procesos de producción y de legitimación de desigualdades socioeducativas en un grupo específico de escuelas secundarias en la ciudad de La Plata (Argentina): aquellos establecimientos dependientes de universidades nacionales. En este escrito nos enfocamos particularmente en el análisis de las miradas de docentes de dichas escuelas acerca de las personas jóvenes que las transitan. Se trata de un grupo de escuelas de prestigio en el imaginario educativo de la capital de la provincia de Buenos Aires que ha modificado su método de admisión, desde el examen eliminatorio hacia el sorteo público, con un discurso democratizador adoptado en el contexto del retorno de la democracia al país en los años ochenta. Una de las escuelas, de especialidad artística, adoptó parcialmente el sorteo en la década de los ochenta y lo hizo por completo ya en el siglo XXI, pero solo a partir del 2015. Ciertamente, constituyen un grupo de instituciones secundarias ligadas a la formación de élites y orientadas en la actualidad hacia el mandato de la inclusión.

En este artículo se entrecruzan dos campos investigativos: el que se refiere a la escuela secundaria y el relativo al campo de estudios juvenológicos. Con respecto a las indagaciones sobre la 
escuela secundaria, como señala Tedesco (2009) en un estudio clásico en el campo, los orígenes del nivel medio en Argentina se ubican en el proyecto de la llamada «república conservadora», específicamente en el decreto de Bartolomé Mitre de 1863, mediante el cual se promulga la creación de los colegios nacionales para formar élites en las capitales de provincia. Sería a mediados del siglo XX cuando surgirían las presiones dirigidas a la masificación del nivel.

Siguiendo a Viñao-Frago (2002), así como la generalización de la educación básica fue la enorme transformación operada durante el siglo XIX y principios del XX, el gran cambio de la segunda mitad del siglo XX fue la generalización del acceso a la enseñanza secundaria. Por ejemplo, la tasa neta de escolarización secundaria en Argentina era del 52,78 \% en el año 1993, mientras que en 2014 alcanzaba el 86,63 \% (si bien persisten brechas según el estrato social de origen tanto en el acceso como, sobre todo, en la graduación $)^{1}$. Sin embargo, como mostraba Braslavsky (1985) en los años ochenta, se conformaban circuitos diferenciados que daban lugar a un sistema educativo segmentado. Tras las reformas educativas de la década de los noventa, surgiría el concepto de «fragmento socioeducativo» en pos de remitir «a un campo estallado caracterizado por las rupturas, las discontinuidades y la imposibilidad de pase de un fragmento a otro. La fragmentación nombra la pérdida de la unidad, la ausencia de referencias comunes» (Tiramonti, 2004, p. 35) y permite conceptualizar el abandono de la referencia a un espacio diferenciado dentro de un campo integrado - propio del concepto de «segmento».

En años recientes, en un contexto de gobiernos «posneoliberales», en varios países de América Latina la obligatoriedad del nivel medio tuvo impulso en términos legislativos: Argentina forma parte, junto con Bolivia, Brasil, Chile, Ecuador, Honduras, México, Paraguay, Perú, República Dominicana, Uruguay y Venezuela, del grupo de países latinoamericanos donde la educación media es obligatoria en toda la extensión del nivel (Di Piero, 2018). Como indica Tenti-Fanfani (2000), la masificación de la escuela secundaria y el cambio de la morfología social de los nuevos inscritos ponen en crisis la oferta tradicional de la educación escolar, lo que da lugar a conflictos y desencantos en relación con las expectativas de los involucrados.

Por otra parte, la irrupción de la juventud como categoría etaria en el campo del conocimiento se remonta a principios del siglo XX y adquiere un impulso renovado en el periodo de entreguerras. En Argentina, los jóvenes y las jóvenes se constituyen como un problema de estudio en el transcurso final de la década de los ochenta (Roberti, 2015). En las proposiciones más biologicistas o demográficas se define a los jóvenes y las jóvenes a partir de la edad biológica y se los designa como un grupo con intereses comunes, ignorando que las divisiones entre edades son arbitrarias y desconociendo las diferencias entre las juventudes (Bourdieu, 1990). Por el contrario, investigaciones recientes han destacado la emergencia de una nueva «condición juvenil» (García-Canclini, Reguillo, Valenzuela-Arce, \& Monsiváis, 2005; Miranda \& Arancibia, 2016) en un contexto de profundas modificaciones sociales, económicas y culturales. En estos estudios se considera a la juventud como un periodo vital, con características propias: no solo representa un periodo de tránsito o moratoria en la vida de los sujetos, sino que es una etapa de gran importancia en sí misma. En este trabajo entendemos, con Feixa (2003), las edades como estadios biográficos culturalmente construidos, que presuponen fronteras más o menos laxas, y de paso, formas en mayor o menor medida institucionalizadas. En ese sentido, lo juvenil no solo está lejos de referirse a un grupo homogéneo, sino que también se articula con factores como el género, la clase, la etnicidad, las redes de sociabilidad, para generar una condición diferenciada o una relación de interseccionalidad (Espinosa-Herrera, Castellanos-Obregón, \& Osorio-García, 2016, p. 1454). Siguiendo a Chaves (2010), es un error llevar el dato biocronológico linealmente a interpretaciones socioculturales que conciben la juventud como un periodo fijo en el ciclo de vida, una fase natural del desarrollo humano en la cual todos entrarán y saldrán en el mismo momento.

Desde este último enfoque, en el presente escrito nos concentramos en las visiones de adultos de un grupo de establecimientos educativos sobre los jóvenes y las jóvenes que transitan en estos. Se

1 Fuente: Sistema de Información de Tendencias Educativas en América Latina, con base en Encuesta Permanente de Hogares. Disponible en http:// www.siteal.iipe.unesco.org/base_de_datos/consulta?i=3\#. 
trata de un grupo de jóvenes en el que la relación de interseccionalidad antes referida se inscribe en el cruce entre lo juvenil, la proveniencia de familias de sectores medios con alto nivel educativo y la escolarización, en un fragmento de instituciones secundarias prestigiosas. Dichas miradas docentes cargan a la juventud actual (a la que entienden como un conjunto homogéneo), con connotaciones negativas que la ligan al facilismo y a la falta de compromiso. Así mismo, construyen una comparación temporal, según la cual tanto la juventud como la escuela eran mejores en el pasado.

Con respecto a la organización de este escrito, en un primer momento nos concentramos en la metodología, y a continuación nos adentramos en la presentación del objeto de estudio, ubicando a estas escuelas en el mapa amplio de secundarias universitarias en el país. En los dos apartados siguientes nos enfocaremos en dos dimensiones constitutivas de las miradas de los docentes: por un lado, las visiones sobre los jóvenes y las jóvenes de hoy teñidas de nostalgia por la escuela secundaria, y los jóvenes y las jóvenes de ayer, y por otro, las perspectivas adultocéntricas sobre estudiantes a los que se exige autonomía. Resulta importante señalar que entre los docentes de las instituciones abordadas conviven enfoques heterogéneos sobre las juventudes, pero a pesar de esto en el presente artículo analizaremos únicamente las visiones de uno de los grupos de docentes encontrados. Por último, presentaremos algunas reflexiones finales en las que mostramos que la añoranza del mérito como criterio rector de la admisión y de la escolarización en estos establecimientos se entrelaza con consideraciones adultocéntricas, en las cuales emerge la nostalgia de un modo de ser joven que, se entiende, corresponde a otra época.

\section{Metodología}

El enfoque metodológico de la investigación se aborda como estudio de caso múltiple desde el paradigma cualitativo. El estudio está centrado en las dinámicas que acontecen en escenarios particulares (Eisenhardt, 1989), que para esta investigación son dos escuelas secundarias dependientes de la Universidad Nacional de La Plata (UNLP), ubicadas en la ciudad homónima. Una de ellas adoptó completamente el mecanismo de sorteo como forma de ingreso desde mediados de los años ochenta, basándose en un discurso «democratizador», y la otra adoptó ese mecanismo de admisión parcialmente en el momento de retorno de la democracia al país, incorporándolo para el total de aspirantes solo a partir del año 2015, en un contexto en el que gravitó una narrativa en favor de la «inclusión» educativa.

Siguiendo la clasificación propuesta por Stake (1995, p. 2), nos inclinamos por el tipo de estudio de caso múltiple «instrumental», en cuanto el interés del estudio no reside solo en el caso en sí mismo, sino que lo moviliza un problema conceptual más amplio y general que, a nuestro juicio, el estudio de estos casos particulares puede iluminar. Como indicábamos en el apartado anterior, en la investigación exploramos procesos de producción y legitimación de desigualdades socioeducativas a través del estudio de dos de las tres instituciones medias dependientes de una universidad nacional situadas en la capital de la provincia de Buenos Aires.

En ese orden de ideas, la selección del caso es intencionada en función de los intereses temáticos y conceptuales que guían el trabajo, en cuanto consideramos que las escuelas elegidas constituyen una expresión paradigmática de un problema socioeducativo más amplio. Como afirma Stake (1995), la cuestión teórica atraviesa los estudios de caso y los explica, esto es, que los estudios de caso no existen naturalmente en la realidad, sino que se trata de construcciones de quien investiga, y es esa persona la que debe explicar por qué vale la pena estudiarlos; vale decir aquí que ninguna de las dos escuelas elegidas constituye un estudio de caso per se.

En cuanto al tipo de muestreo, partimos de una muestra multietápica: en primer término, escogimos clústeres intencionalmente, y entre estos hacemos una selección aleatoria ${ }^{2}$. Es decir, en

2 Según Stake (1995), las muestras pueden clasificarse en aleatorias (probabilísticas) y no aleatorias (no probabilísticas). En aquellas aleatorias, cada componente del universo tiene la misma probabilidad de ser seleccionado, y el error puede estimarse. Existen varias posibilidades para seleccionar los componentes en una muestra probabilística. Una de ellas es la utilización de un marco muestral, es decir, un listado exhaustivo de todos los componentes del universo, al cual se aplica luego una tabla de números aleatorios, esto es, con números que no siguen ningún orden. Otras muestras 
un primer momento seleccionamos ad hoc dos escuelas dentro de cierto grupo, y hacia el interior de estas combinamos la realización de entrevistas en profundidad a ciertos actores clave, con una selección al azar de docentes también consultados ${ }^{3}$.

Ubicando cronológicamente la fase de toma de datos, hay que precisar que entre los años 2012 y 2016 se hicieron observaciones, se entrevistó en detalle a 13 actores «claves» para las instituciones (directivos, jefes de departamentos, secretarios de extensión y secretarios académicos de las escuelas y de la universidad), se efectuaron entrevistas semiestructuradas a 67 docentes seleccionados de modo aleatorio, se revisaron las actas taquigráficas ${ }^{4}$ del momento en que se discutía la modificación del método de admisión en el Consejo Superior de la universidad en los años ochenta y se recuperó un corpus compuesto por seis documentos institucionales que incluyeron información sobre las fichas sociodemográficas de los ingresantes.

\section{Dos escuelas de pregrado}

Son 51 las escuelas dependientes de universidades nacionales en Argentina y 57 las universidades nacionales en el año 2018. La Universidad Nacional de La Plata, una de las más antiguas y prestigiosas, cuenta con tres niveles: pregrado, grado y posgrado. Al primero de ellos pertenecen seis establecimientos (cinco de educación secundaria y uno de primaria), los cuales funcionan como dependencias de la presidencia de la universidad: un secundario con orientación agrotécnica se ubica en la Estación Valdés del Partido de 25 de Mayo (provincia de Buenos Aires) y los otros cinco en la ciudad de La Plata. Las cuatro escuelas medias de «pregrado» presentes en la ciudad se ubican en el casco urbano central de la capital de la provincia de Buenos Aires.

En el siguiente mapa podemos ubicar las secundarias universitarias estatales en el país, considerando el momento histórico en que las crearon:

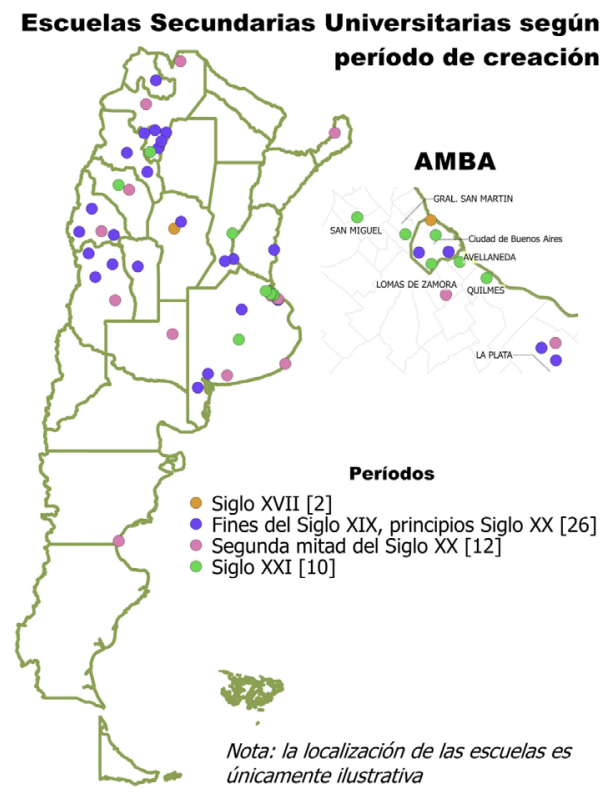

probabilísticas son las sistemáticas: se puede sortear el punto de arranque y después contar cada diez. Otra es la estratificada: teniendo estratos, selecciono aleatoriamente localidades, dentro de estos selecciono barrios, y dentro de estos, casos. Otra muestra es por clústers: se selecciona un barrio y se releva todo el barrio entero. Lo aleatorio en ese caso es la selección del barrio, ya que después funciona como un censo. En la presente investigación optamos por una muestra sistemática: se tomó el listado de docentes de cada escuela, y a partir de un punto de arranque se hizo el conteo, considerando formaciones disciplinares diversas.

3 Cabe aclarar que a los fines de preservar el anonimato, los nombres de las instituciones mencionadas y de los docentes son ficticios, siendo identificados estos últimos por características consideradas relevantes tales como el género, la edad, el cargo o la disciplina de pertenencia.

4 Entendidas aquí como las actas en las cuales se transcribieron los discursos de los actores que discutían los mecanismos de admisión en el Consejo Superior de la universidad. 
La Escuela 1 es uno de los cuatro establecimientos secundarios de pregrado dependientes de la Universidad Nacional de La Plata localizados en la ciudad homónima. Podemos ubicarla en el primero de los cuatro grupos señalados en el mapa, debido a que la fundaron en 1907, dos años después de que ocurriera la nacionalización de la universidad provincial, ante la demanda de una educación preuniversitaria femenina frente a la existencia del Colegio Nacional, destinado únicamente a varones. En un primer momento esta escuela, cuyo nombre hasta los años sesenta fue Colegio Secundario de Señoritas (CSS $)^{5}$, funcionaba en el piso superior de la Escuela 3. El edificio actual, situado en el centro de la ciudad, había sido sede de la Escuela Normal de Maestras (hoy, escuela exnormal 1).

Al igual que las otras tres instituciones secundarias dependientes de la Universidad Nacional de La Plata presentes en dicha ciudad, la Escuela 2 se localiza también en el casco céntrico. Situada a dos cuadras de distancia de la Facultad de Bellas Artes de la misma universidad, esta institución es un bachillerato con especialidad artística que se propone articular conocimientos de las ciencias humanas y naturales con saberes relacionados con los lenguajes artísticos de la música y de las artes visuales.

De ese modo, la Escuela 2 data de una fundación más reciente que las centenarias escuelas 1 y 3 (la Escuela 4, de orientación técnica, inició su funcionamiento en el año 2018). Se estableció gracias a la iniciativa de un grupo de profesores de la Escuela Superior de Bellas Artes (hoy convertida en facultad), quienes posibilitaron la transformación de la Escuela de Dibujo de la universidad en un bachillerato especializado. Sus comienzos se remontan al año 1949 con la creación del ciclo básico dentro del área de extensión, que incorporaba alumnos de escuelas primarias en los últimos tres años, los cuales pasaban primero por el ciclo básico, luego por la Escuela de Dibujo y después por la Escuela Superior de Bellas Artes. En 1956 esta configuración se regularizó y se creó la Escuela 2, que celebró en el 2016 sus 60 años de fundada; corresponde, de ese modo, al tercero de los grupos indicados en el mapa.

\section{4. «Por sorteo entra cualquiera» o la añoranza de una juventud meritoria}

Yo creo que demasiado exigente no hay nada ahora. (Nadia, jefa del Departamento de Letras, Escuela 1)

¿Hacerse la rabona? Ni pensarlo. Como sus compañeritas mayores, no sentían la exigencia como una carga sino como un privilegio: el camino abierto a la universidad. (Universidad Nacional de La Plata, \& Liceo Víctor Mercante, 2001, pp. 44-45)

En este apartado nos enfocamos en el análisis de las miradas de un grupo de docentes que impugna las políticas de admisión abierta o irrestricta, objeción que se entrelaza con la condena de los estudiantes y las estudiantes «de ahora»: en ese sentido, los docentes sostienen que «por sorteo entra cualquiera». El significante «cualquiera» connota, así, a jóvenes que no se esfuerzan para ganarse el lugar y no saben «aprovechar la oportunidad» que significa estar en estas instituciones educativas, entendidas como guetos de la calidad en el sector público de la educación secundaria. Estos docentes abogan por el retorno de la exigencia y la calidad, y se posicionan contra políticas de admisión y retención que, desde sus miradas, socavan el mérito como justo asignador de posiciones. Igualmente, manifiestan inquietudes relacionadas con la educación de «los más capaces», sosteniendo que se descuidaría a aquellos «estudiantes buenos» al enfocar las acciones en los más desaventajados.

Se trata de docentes que, como también se indicara en otros estudios (Larrondo, 2012; Mayer, 2009; Noel, 2006), construyen a sus estudiantes calificándolos desde la negatividad o la carencia, activando narrativas conservadoras y nostálgicas respecto de la escuela selectiva del pasado, y homologando

5 Se lo conoció con diferentes nombres desde su fundación: Colegio Secundario de Señoritas (1907-1952 y 1955-1957), Colegio Secundario de Señoritas Eva Perón (1953-1955), Colegio Secundario de Señoritas Víctor Mercante (1957-1959), y con su nombre actual desde 1960 (por Ordenanza 21 de diciembre de 1959), año en que comenzó a ser mixto. 
desempeño escolar y disciplina con cuestiones sociales, culturales, étnicas y económicas (Mayer, 2009, p. 90). De ese modo, activan prácticas y discursos discriminatorios, asentados en prejuicios étnicos, socioeconómicos o xenofóbicos (Tenti-Fanfani, 2006).

En lo que tiene que ver con el concepto de «representaciones sociales», Moscovici (1961) lo propone, al tiempo que subraya el carácter dinámico de estas y toma distancia de la noción durkheimiana de representaciones colectivas. Son construcciones simbólicas originadas en la interacción social y recreadas en la relación entre grupo e individuo. Jodelet (1986), por su parte, define las representaciones sociales como un saber de sentido común, un conocimiento práctico orientado a la comprensión del entorno: se trata de un conocimiento elaborado socialmente que el sujeto recibe, pero también reelabora y reinterpreta, produce y reproduce. Esta dimensión resulta importante, ya que los discursos de los sujetos no surgen en el vacío, sino que se relacionan con concepciones presentes en la sociedad y en las políticas mismas; en consecuencia, los actores hablan y son hablados por los discursos. Ese conocimiento se constituye, a su vez, en una guía orientadora para la acción, en una conductora de las prácticas.

A continuación presentaremos una selección de representaciones sociales de docentes, directivos, secretarios/as académicos/as y jefes/as de departamento de las escuelas en torno a la condición juvenil. Así mismo, se trata de formas de saber práctico en cuanto remiten a la experiencia y sirven para actuar sobre la realidad (Jodelet, 1986).

En consonancia con la noción de mérito propia de la modernidad, en la que se entendía por posiciones sociales justas aquellas que se alcanzan a partir de la competencia entre hombres libres de condicionantes ligados al nacimiento o la herencia, entre los docentes que componen este grupo se presupone que la competencia por las vacantes produciría una desigualdad justa basada en el mérito individual. En palabras de una profesora de Ciencias Naturales de 67 años:

«El sorteo es menos selectivo. Por examen entran los más capaces, por sorteo entra cualquiera. Ha bajado el nivel. A los chicos no les importa; cuanto menos trabajás, mejor, pasás igual.» (Docente $\mathrm{n}^{\circ} 22$, Escuela 1)

Tal como indica Dubet (2004) en relación con algunos supuestos que pueden rastrearse detrás de cierta retórica cargada de nostalgia por el pasado, en la medida en que el mandato que pesa sobre el nivel medio ya no es el de la selección, la escuela secundaria no puede desprenderse de los estudiantes que le causan problemas con la misma facilidad con la que lo hacía antes. Muchas veces, en los discursos de docentes y demás actores internos y externos a la escuela, los defectos del pasado son olvidados y encubiertos por la añoranza: «En Francia basta ver cómo los análisis de Bourdieu y Passeron han desaparecido del imaginario colectivo en beneficio de un embellecimiento del pasado, de los 'buenos y viejos tiempos' en que la escuela republicana parecía armonizar con la sociedad» (Dubet, 2004, p. 28).

En ese orden de ideas, el carácter obligatorio que asume la escuela secundaria en Argentina a partir de la sanción de la Ley de Educación Nacional 26206 del 2006 tracciona los sentidos que los actores del sistema educativo, y la sociedad en general, connotan a este nivel del sistema educativo. En el caso particular de los docentes de esta escuela, aparecían tensiones en relación con aquello que dicha normativa promueve, en tanto que, frente a un mandato que impulsa la inclusión de todos y todas en la escuela, se mostraban preocupados por la educación de «los más capaces» y por la decadencia del nivel educativo. La crítica se dirigía a que se estaría descuidando a aquellos «estudiantes buenos» al enfocar las acciones sobre los más desaventajados. En palabras de una docente de 60 años, licenciada en Química:

«Se excluye a los que más pueden. También debería haber estrategias para los que más pueden, no solo para los que menos. El principal objetivo es generar buenos ciudadanos, pero no debe dejarse al margen la formación en la excelencia.» (Docente $n^{\circ} 20$, Escuela 1)

En estos casos, la respuesta al consultar si consideraban que, a partir de la implementación del sorteo, la composición sociocultural de la matrícula se había vuelto más heterogénea era negativa, sustentaba la posición que abogaba por el retorno al examen. La lógica de dicho argumento apuntaba 
a que si el sorteo no impacta en la composición de la matrícula y, además de ello, deja afuera a muchos que son «capaces» (al ceder al azar el reparto de los preciados bancos), entonces resulta más conveniente un examen como método de ingreso que, al menos, asegure que quienes efectivamente acceden se «esforzarán» para sostenerse allí.

Una docente entrevistada, a quien hemos llamado Nadia, jefa del Departamento de Letras y que se desempeña tanto en la Escuela 1 como en la Escuela 3, respondía así a la pregunta acerca de si el cambio de la metodología de ingreso, desde el examen hacia el sorteo, había logrado modificar la composición social de la escuela:

«La composición social no. Y eso te lo deben contestar mucho... pero es una mentira. Es que modificó la composición académica y no la social, ese es el tema (...) Sí el nivel, pero lo social no. Yo te diría que hubo algo.... mínimo mínimo, mínimo... Sí, cada tanto aparece, pero no sé si no aparece un cambio importante con el examen (...) Digamos que la heterogeneidad pasa por un lado, pero el nivel académico debería pasar por otro.» (Nadia, jefa del Departamento de Letras, Escuela 1)

Así las cosas, desde su punto de vista se trata de escuelas colonizadas por parte de un sector de la clase media platense, independientemente del mecanismo de ingreso en curso. Adicionalmente, ella respondía de modo contundente a la pregunta sobre si estaba de acuerdo o en desacuerdo con la decisión de acabar con los exámenes:

«L.: Creo que no te lo tengo que ni contestar: en desacuerdo.

E.: ¿Y por qué estás en desacuerdo?

L.: Porque se optó por la opción más fácil, que fue la supresión del examen, sin pensar en una solución alternativa que democratizara el acceso pero con las instancias académicas. Me parece que era o examen con las condiciones que tenía, o no examen, y no se pensó en una instancia media que podría haber sido muy rica.

E.: ¿Estaba muy polarizada la opción?

L.: Sí, se decidió así; era como un planteo dicotómico.»

(Nadia, jefa del Departamento de Letras, Escuela 1)

Nadia es una persona reconocida en la institución, con un cargo de jefatura de uno de los departamentos docentes. Así mismo, desde el grupo de docentes que sostienen el sorteo como metodología de ingreso más justa, ella es identificada como representante de una postura «retrógrada». Específicamente, al consultarle por la implementación del sorteo, respondía:

«E.: ¿Estás de acuerdo o en desacuerdo con la implementación del sorteo?

L.: En desacuerdo.

E.: ¿Y por qué el sorteo no te parece adecuado?

L.: Porque no me parece que atienda a un concepto que a Flacso no le gusta pero que yo valoro, que es el mérito y el esfuerzo ${ }^{6}$. Yo creo que todos tenemos una historia y vale.»

(Nadia, jefa del Departamento de Letras, Escuela 1)

Como indica Rawls (1993), el mérito se presenta como una norma de justicia porque aparece como la manera de construir las desigualdades justas en una sociedad que valora la igualdad de los individuos. Si se considera que todos somos iguales y, a la vez, que toda sociedad clasifica a los individuos, eso solamente puede hacerse a partir del momento en que individuos libres ponen en juego sus talentos y su trabajo. De otro modo, no habría un criterio más que el nacimiento o echarlo a la suerte para formar alguna escala de estratificación. El mismo Rawls, a pesar de sus dudas fundamentales sobre el mérito, no imagina otras maneras de construir las desigualdades justas en un mundo donde la igualdad y la libertad son los principios de justicia. Es porque el mérito es una forma productiva de combinar igualdad y libertad en una sociedad moderna, que ese principio de justicia es fundamental.

6 Este punto resulta sugestivo porque la docente presentaba su propia postura, marcando un contrapunto con las producciones de esta institución, a las que asociaba al mandato de la inclusión en la escuela secundaria imperante en Argentina en el contexto de obligatoriedad de la escuela secundaria. 
En conclusión, desde las miradas de este grupo de docentes se considera que la exigencia es un valor que la juventud actual no estima, porque «a los chicos no les importa, pues cuanto menos trabajás, mejor, pasás [de año] igual». En contraposición, se construye una imagen homogénea de «los jóvenes y las jóvenes de ayer» como seres esforzados y meritorios que valoraban el hecho de transitar por estos colegios como una oportunidad. Las dos imágenes presentes en las formulaciones enunciativas que aquí recuperamos comparten características en relación con su carácter universalista, estático y monolítico y producen una nueva «invención de la juventud, como categoría objetivada y fuera de la historia» (Kriger, 2014), y teñidas por el déficit (Larrondo, 2012).

Como indica Chaves, «se parte de una comparación con perspectiva adultocéntrica, la definición se hace por diferencia de grado en relación con el parámetro elegido, lo que lleva a establecer características desde la falta, las ausencias y la negación, y son atribuidas al sujeto joven como parte esencial de su ser» $(2005$, p. 11). Teniendo en cuenta las miradas de los docentes y retomando las ideas de Chaves, es posible pensar que en estos discursos se pierde de vista el carácter social de la condición juvenil, naturalizando visiones ideologizadas y discriminatorias sobre este grupo.

A renglón seguido nos enfocaremos en un requerimiento que se demanda especialmente a los jóvenes y las jóvenes que aspiran a hacer su escolarización en este grupo de escuelas de pregrado: la autonomía.

\section{Visiones adultocéntricas: de la autonomía como exigencia}

La imagen del joven esperado en la institución que se construye está signada por el tipo ideal del «alumno autónomo». En ese sentido, la autonomía se exige como premisa y no como punto de llegada, desde un reclamo adultocéntrico que no considera las diferencias que los estudiantes traen en su biografía, así como también las edades de quienes se escolarizan (que en una de las escuelas van desde los 12 hasta los 19 años). Así, se predica sobre los estudiantes, infantes y jóvenes, como si se tratara de la franja etaria de 18 a 19 años, exclusivamente. De este modo, la categoría moderna de «alumno» como un sujeto único, indiferenciado y monolítico reaparece entre enunciadores que predican sobre ellos desde una pedagogía que, anclada en la modernidad, no distingue particularidades.

En esa línea, una docente del Departamento de Ciencias Naturales, que trabaja en la Escuela 1 desde 1978, sostenía que volvería al examen como metodología de ingreso y se posicionaba en contra de medidas que buscaran apuntalar una escolarización desregulada:

«Porque eso [el examen de ingreso] no quita que entren todos. Debe ingresar todo el mundo siempre que sepa, que demuestren idoneidad: primero demostrá que sos capaz, no puede ser al voleo. Con este sistema actual, de los buenos nadie se ocupa. ¿De la gente buena quién se ocupa? Siempre estamos ahí con el apuntecito, y los buenos reclaman, porque nivelamos para abajo y se desperdician los buenos. ¿Para qué estudiar y sacar un buen promedio, si da igual...?» (Docente $\mathrm{n}^{\circ} 22$, Escuela 1)

Como se puede inferir aquí, la frase «Siempre estamos ahí con el apuntecito» busca posicionarse críticamente sobre algunas medidas de retención implementadas por la última gestión directiva en la escuela, a partir de la cual se dio lugar a programas de apoyo a los estudiantes que presentaran dificultades en su escolarización. Al respecto, la docente de Letras también indicaba:

«E.: Pensando en el caso de esta escuela, ¿por qué te parece que se produce el abandono? L.: Pues no sé... porque esta escuela, si por algo se caracteriza, es por apoyar mucho, demasiado a veces; es agobiante la cantidad de cosas que se hacen... porque yo siempre discuto [indicación para la ayudante del departamento]. Vos tenés que salir de tu espacio y generar algo... [me pregunta:] ¿Una sola [opción] tenés que poner?

E.: No, podés poner varias si te parece...

L.: Después... los problemas de familia los están empezando a ver, afectan mucho. Y que la familia no dé el apoyo también es algo... Sobre todo lo otro, te digo honestamente, hasta a mi juicio es políticamente incorrecto. Los acompañamos demasiado... Si consideramos que 
uno de los valores es que salgan independientes y autónomos... llega un momento en que... Nosotros discutimos, a veces lo damos [el apoyo], pero bueno, en algún momento te tenés que fijar solo...» (Nadia, jefa del Departamento de Letras, Escuela 1)

En afirmaciones tales como «Los acompañamos demasiado»o «En algún momento te tenés que fijar solo», es posible captar el énfasis puesto en la autonomía entendida a modo de premisa, como una cualidad con la cual los estudiantes deben contar para transitar la escolarización en esta institución. Igualmente, es posible observar que estos discursos van de la mano de la consideración de que el sorteo no garantiza una mayor heterogeneidad en la composición sociocultural de la matrícula, así como de que la clase media necesita «cultivar» un «refugio» en el cual seguir subsistiendo y conservando una educación para sí con cierto nivel académico, aunque eso implique poco o nulo contacto con el resto de los sectores de la sociedad. Se trata de un grupo de escuelas que se consolida como una especie de «gueto de la calidad» en el sector público:

«Insisto, es un $5 \%$, que quizás... si seguimos atendiendo a la clase media, un poquito más alta, un poquito más baja, pero... Entonces estamos desertando de ser una educación de calidad para ese sector, que también a mi me parece un sector importante porque de algún modo son las clases medias las que después se profesionalizan, hacen un montón de cosas... En cambio los chicos más marginados, ya te digo, habrá un 4 o un $5 \%$, el porcentaje es muy bajo» (Nadia, jefa del Departamento de Letras, Escuela 1).

Ciertamente, la preocupación que estructura estas narrativas se refiere a garantizar la calidad académica. Al consultarle por el método de ingreso más justo, esta docente explicaba: «L.: Yo armaría, tipo el [colegio] Nacional Buenos Aires ${ }^{7}$, un curso a contraturno de la primaria, que fueran los mejores profesores que pudiera conseguir, que exigiera, que vean lo que la escuela primaria... Mientras tanto, apuntaría a ver si reforzamos la primaria. Miremos esta historia en perspectiva: cuando mi padre ingresó en la Escuela 3, no se fue a preparar. Habia examen, la primaria era buena y te habilitaba para dar el examen. Es decir, también tenemos que ver que desde los setenta para acá hubo un deterioro en la primaria que generó que el ingreso fuera un monstruo que había que vencer... Pero digamos por eso digo que las cosas tienen su historia. Entonces el deterioro de la primaria generó, de algún modo, otra cuestión; no sé si me estoy explicando. Entonces yo haría el curso de ingreso con evaluaciones, insisto. No un curso de ingreso ficcional, es decir, como para la pantalla de la democracia, sino un curso de ingreso dado por los mejores profesores, donde se inscribirían todos los que quieran, con aprobación de exámenes parciales y después... Yo por eso te digo que mi criterio es el mérito, ahora lo desvirtúan diciendo la meritocracia.

E.: Es complejo...

L.: Porque cuántas veces queda fuera, y antes al menos después hacían ese extremo esfuerzo que era dar equivalencias.

E.: Eso para ingresar después, ¿no?

L.: Era, ahora ya no existe. Entonces, vos dejás afuera a chicos ... y tenés chicos que se matriculan y no les importa, les da igual.» (Nadia, jefa del Departamento de Letras, Escuela 1).

De ese modo, esta docente también revaloriza el mérito como justo asignador de posiciones y critica que el sorteo dé lugar a estudiantes a los que «no les importa nada», quienes no saben «aprovechar» la oportunidad que significa ocupar un banco en esta escuela. En ese sentido, incluso ella, que defiende la necesidad del ingreso por examen puro, propone que la misma institución se haga cargo de las desigualdades iniciales y brinde un curso de ingreso a contraturno, a partir del cual los estudiantes puedan competir en igualdad de oportunidades por un banco, dejando de lado las desigualdades surgidas a raíz de su trayectoria de escolarización primaria.

7 Como señala Méndez, desde 1957 en el Colegio Nacional Buenos Aires rige el examen obligatorio (2013, p. 80). A partir de 1987, la institución brinda un curso de ingreso obligatorio y desde ese año se llevó a cabo un plan piloto en el que el examen se desdobló en varios parciales que se promediaban por materia, que cursaban los alumnos de séptimo grado de la primaria. 
En el caso del bachillerato artístico, uno de los docentes agregaba que existen otros colegios donde insertarse en La Plata, pero este tiene el deber de marcar la diferencia porque se trata de una escuela piloto:

«Esta era una escuela piloto. Cuando era una escuela como la gente, de excelencia, teníamos 25 alumnos. Depende de cómo lo quieran enfocar, pero la calidad educativa empeoró, y la timba tampoco sirve. Con el sorteo estamos apostando a la timba. Cuando era por examen de ingreso, entraban los mejores. Ahora igualaron hacia abajo.» (Docente $\mathrm{n}^{\mathrm{o}} 34$, Escuela 2)

Ciertamente, desde una visión nostálgica denunciaba el crepúsculo de la posición de las escuelas preuniversitarias como focos o guetos de calidad educativa. Vale la pena indicar que, en el caso de la Escuela 2, la mayoría de las posturas que abogaban por el retorno del examen de admisión se concentraban en el edificio Anexo, es decir, en el área de música, y, dentro del edificio Noche de los Lápices, específicamente en el Departamento de Ciencias Exactas.

A continuación recuperamos una observación participante que también ilustra el desencanto ante una supuesta «decadencia educativa en las escuelas de la UNLP». Con ocasión de la realización de las Jornadas Extenso en el año 2015 en la Escuela 2, dos profesores desarrollaban un trabajo en una mesa en la cual se presentaban los avances anuales en tres disciplinas: por un lado, en la asignatura «Producciones accesibles sobre discapacidad»; por otro, en una revista, y por último, en la asignatura «Ambiente y diseño». Cuando comenzó la exposición, la secretaria me tomó como referente visual al hablar, me presentó y les explicó a los expositores que soy ajena a la escuela, y me expuso que las materias optativas se abren por año, dependiendo del cupo de estudiantes interesados en ellas. En el caso de la asignatura «Ambiente y diseño», dictada en sexto año de la Escuela de Educación Secundaria y perteneciente al Departamento de Discursos Visuales, el equipo docente ha elaborado una presentación en Power Point que denominaron «Educación y diseño: derecho y deber», en la que no se abocaron a presentar lo trabajado durante el curso, sino que desplegaron una serie de ideas sobre la educación.

Al empezar, al docente que advirtió «Yo digo lo que pienso en cualquier espacio que tenga», anunciando que dirá algo, al menos provocador, días antes lo había encontrado en la sala de profesores, cuando me hallaba entrevistando a otra docente. En esa oportunidad, él me había expresado que tenía mucho para decir sobre «el tema de la decadencia educativa de las escuelas de la UNLP», y que, si me interesaba, me acercara a la mesa en la que él participaría en las Jornadas Extenso. Ya en ocasión de su exposición, advirtió que debe problematizarse la idea de retención, en cuanto la misma debe ser producto de la propia voluntad de permanecer y no ser forzada. Buscando evidenciar su preocupación en torno a la «decadencia educativa», mostró las fotos de un limpiavidrios y de un cartel en una zona de Berisso en el que figuraban palabras con faltas de ortografía. En la siguiente filmina preguntaba: «¿Estamos conformes con la formación de los conciudadanos?». Entonces desplegó una serie de ideas en relación con que hoy a los estudiantes solo les importa «estar conectados» a sus celulares. En el modo de ver del docente, la idea de retención es discutible en cuanto la permanencia o no en la escuela debería ser una decisión tomada autónomamente por los propios estudiantes y no una «imposición» hecha por la obligatoriedad de la escolarización.

Así, en pos de dar lugar a la libertad, se promueven trayectorias desreguladas y desiguales por cuanto cada quien queda librado a sus propios recursos para permanecer. La exigencia de autonomía como punto de partida es individualizante y descansa en una ideología meritocrática, debido a que está íntimamente relacionada con la capacidad de mostrar la propia capacidad de adaptación a la propuesta escolar, invisibilizando el peso de los soportes colectivos y las socializaciones previas. Como asegura Young (1961) en su narración crítica de un mundo distópico (situado en 2033, es decir, tres cuartas partes de siglo más tarde desde la visión del autor, pero a menos de quince años desde nuestro punto de vista actual), en el sistema «meritocrático» de educación todos se deben dar la misma oportunidad de acceder a trabajos concomitantes con sus habilidades. Sin embargo, la meri- 
tocracia nunca prometió igualdad, solo que las desigualdades se distribuirían más equitativamente, creando una «aristocracia de los talentos». El mérito, en la propuesta escolar del grupo de secundarias universitarias, se transfigura hacia la exigencia de autonomía. Esa autonomía se define, además, desde una concepción adultocéntrica que la mide y evalúa en comparación con los comportamientos que se esperarían en un adulto. En tal sentido, el alumno absorbe al joven como sujeto que excede el ámbito de la escuela y se desconoce la posibilidad de que los jóvenes y las jóvenes actúen autónomamente en otros espacios que no sean el específicamente escolar.

Los aportes de Van Zanten (2003), al analizar las expectativas escolares de padres de clase media blanca en la periferia parisina, resultan significativos en cuanto dialogan con los hallazgos de esta investigación. Desde el contexto europeo, la autora señala que el rechazo y la sospecha de dichos padres sobre los estudiantes pobres no se deben a un racismo o clasismo espontáneo, sino a que esos alumnos son construidos como un peligro para el desarrollo académico, social y personal de sus hijos (2003, p. 109). También en nuestro caso, los «otros indeseables» descritos por los enunciadores aparecen como amenazas para la calidad y la excelencia educativa.

Para concluir, el caso de este grupo de docentes que propone el retorno del mérito como criterio se fusiona con una retórica que valora el esfuerzo y la autonomía que, al parecer, caracterizaban a una juventud que delinean vagamente como «de otra época» y critican las políticas públicas enfocadas en sectores desfavorecidos. Así, se pretende valorizar la idea de merecer ligada a una crítica social más amplia, dirigida a los sectores que reciben ayuda sin haberse «esforzado lo suficiente», y se impugna a esos sectores como si todos partieran del mismo punto en el momento de la competencia.

Aquí es importante acudir a Van Zanten (2008), quien se refiere al «mito meritocrático» como uno de los mecanismos de cierre de la enseñanza superior selectiva. De este modo, la meritocracia constituye un punto de apoyo principal en sistemas democráticos en los que las desigualdades ligadas al sostenimiento de posiciones profesionales y sociales mejor remuneradas y más prestigiosas que otras se legitiman si se producen en el marco de una igualdad de oportunidades para obtenerlas, y el valor de los individuos es sancionado por una institución social neutra como, se supone, sería la escuela.

En tal sentido, esa retórica cargada de nostalgia por la educación del pasado es atravesada por la añoranza de los «jóvenes de ayer»: en las miradas de estos docentes, la decadencia educativa de las escuelas de la UNLP se imbrica con el desencanto frente a jóvenes a los que solo les importaría «estar conectados» a sus celulares. Estos jóvenes se transforman, en términos de Van Zanten, en «otros indeseables» que atentan contra la calidad y amenazan la excelencia educativa, jóvenes que se encuentran bien distantes de la construcción imaginaria del heredero del sistema o de un «joven oficial» en palabras de Margulis y Urresti (1998). Por el contrario, sostenemos con Núñez y Litichever que «los jóvenes no son como solían ser los alumnos tiempo atrás ni como hoy quisiéramos que sean. Mucho menos como creemos que éramos nosotros de jóvenes (...) es necesario pensar desde las coordenadas actuales» $(2015$, p. 11).

\section{Reflexiones finales}

En este trabajo nos enfocamos en el análisis de una construcción discursiva de cierto grupo de docentes de escuelas secundarias dependientes de una universidad nacional. Se trata de miradas que destacan un pasado de «escuelas piloto» en el que accedían los mejores alumnos, en contraposición a un presente de escuelas en decadencia en el que los alumnos «vienen a zafar ${ }^{8}$ » 0 «solo les importa estar conectados a sus celulares». En estas visiones, la añoranza del mérito como criterio rector de la admisión y de la escolarización se entrelaza con la nostalgia de un modo de ser joven que, se entiende, corresponde a otra época. En ese sentido, el rechazo de estos estudiantes no guarda relación con el racismo o el clasismo, sino con el hecho de que se considera que atentan contra el desarrollo académico y la excelencia tradicional de tales escuelas.

8 «Zafar», como acepción coloquial, se refiere a intentar desentenderse de una obligación o librarse de un compromiso. 
En estos discursos en los que se añora la edad de oro perdida y se protesta frente a la decadencia educativa, se entrelazan visiones sobre el declive general de la educación con visiones sobre el declive de la juventud. Se idealiza así un pasado dorado, en el que cierto tipo de joven transitaba por cierto tipo de escuela, en contraposición a los jóvenes y las jóvenes que estudian actualmente en las escuelas secundarias en general y, en particular, este grupo de secundarias de prestigio en el imaginario educativo platense. Cabe anotar que, más allá de la existencia de «tendencias contrapuestas» (Kessler, 2014), desde 2006 la educación secundaria en Argentina se constituyó como un derecho a ser garantizado por el Estado, lo cual tensiona los sentidos con los que, en general, se ha concebido a este nivel, dirigido originalmente a un sector minoritario de la población.

Así mismo, esas miradas sobre la juventud se convierten en guías orientadoras para la acción, es decir, en conductoras de prácticas. Tal como lo indica Jodelet (1986) al definir el concepto de representaciones sociales, se trata de formas de saber práctico en cuanto remiten a la experiencia y sirven para actuar sobre la realidad. De ese modo, no es casual que el grupo de docentes en el cual nos concentramos en este artículo corresponde en su mayoría a los departamentos de Letras y Ciencias Exactas, y que es precisamente en esas disciplinas en las que se registra el mayor número de estudiantes desaprobados/as.

En conclusión, entendemos que, en estas miradas (que no son las únicas dentro de estas instituciones), aquello que se predica sobre el estudiantado se solapa con consideraciones normativas y adultocéntricas sobre las juventudes actuales. En ese orden de ideas, en dichas visiones se considera a la juventud como un sujeto homogéneo y como una categoría universal e indistinta que se reconoce en una manera de ser joven, en singular. Como indica Urresti, «para comprender a los jóvenes es preciso, más que pedirles o juzgarlos por aquello que hacen o no hacen respecto de los jóvenes de generaciones anteriores, comprenderlos en su relación con la situación histórica y social que les toca vivir» (2000, p. 178).

\section{Lista de referencias}

Bourdieu, P. (1990). La juventud no es más que una palabra. En P. Bourdieu (Ed.), Sociología y cultura (163-173). México, D. F.: Grijalbo.

Braslavsky, C. (1985). La discriminación educativa en Argentina. Buenos Aires: Flacso, Grupo Editor Latinoamericano.

Chaves, M. (2005). Juventud negada y negativizada. Representaciones y formaciones discursivas vigentes en la Argentina contemporánea. Última Década, 23, 209-232.

Chaves, M. (2010). Jóvenes, territorios y complicidades. Una antropología de la juventud urbana. Buenos Aires: Espacio Editorial.

Di Piero, E. (2018). Pasado y presente de la escuela secundaria en Argentina. Políticas de admisión a secundarias universitarias. En C. Suasnabar, L. Rovelli, \& E. Di Piero (Comps.), Análisis de política educativa en la Argentina: teorías, enfoques y tendencias recientes (pp. 54-77). Ciudad de La Plata: Editorial Edulp.

Dubet, F. (2004). ¿Mutaciones institucionales y/o neoliberalismo? En E. Tenti-Fanfani (Org.), Gobernabilidad de los sistemas educativos en América Latina. Buenos Aires: Iipe-Unesco.

Eisenhardt, K. M. (1989). Building theories from case study research. Academy of Management Review, 14(4), 532-550.

Espinosa-Herrera, G., Castellanos-Obregón, J. M., \& Osorio-García, D. (2016). Condición juvenil y drogas en universitarios: el caso de una universidad regional. Revista Latinoamericana de Ciencias Sociales, Niñez y Juventud, 14(2), 1451-1468. doi:10.11600/1692715x.14238060615

Feixa, C. (2003). Del reloj de arena al reloj digital. Sobre las temporalidades juveniles. Jóvenes. Revista de Estudios sobre Juventud, 7(19), 6-27. 
García-Canclini, N., Reguillo, R., Valenzuela-Arce, J. M., \& Monsiváis, A. (2005). Planteamiento conceptual de la Encuesta Nacional de la Juventud 2005. La condición juvenil. Formas de institucionalización, cambio y continuidad en el México contemporáneo. México, D. F.: Instituto Mexicano de la Juventud, Centro de Investigación y Estudios sobre Juventud, Secretaría de Educación Pública.

Jodelet, D. (1986). Representaciones sociales: contribución a un saber sociocultural sin fronteras. En D. Jodelet, \& A. Guerrero (Eds.), Develando la cultura. Estudios en representaciones sociales. México, D. F.: Facultad de Psicología-Unam.

Kessler, G. (2014). Controversias sobre la desigualdad. Argentina, 2003-2013. Buenos Aires: Fondo de Cultura Económica.

Kriger, M. (2014). Politización juvenil en las naciones contemporáneas. El caso argentino. Revista Latinoamericana de Ciencias Sociales, Niñez y Juventud, 12(2), 583-596. doi:10.11600/169271 $5 \mathrm{x} .1225310314$

Larrondo, M. (2012). ¿Nuevos alumnos? La construcción de la identidad escolar en nuevos dispositivos de educación media. Un estudio de casos en contextos de pobreza de la ciudad de Buenos Aires. Propuesta Educativa, 37(21), 109-111.

Margulis, M., \& Urresti, M. (1998). La construcción social de la condición de juventud. En H. Cubides (Ed.), Viviendo a toda. Jóvenes, territorios culturales y nuevas sensibilidades. Bogotá, D. C.: Siglo del Hombre Editores.

Mayer, L. (2009). Escuela, integración y conflicto. Notas para entender las tensiones en el aula. Educación, Lenguaje y Sociedad, 6(6), 85-112.

Méndez, A. (2013). El colegio. La formación de una élite meritocrática en el Nacional Buenos Aires. Buenos Aires: Sudamericana.

Miranda, A., \& Arancibia, M. (2016). El futuro está incompleto: la construcción de trayectorias laborales sobre principios del siglo 21. Revista Trabajo y Sociedad, 28, 195-217.

Moscovici, S. (1961). La conciencia social y su historia. Representaciones sociales: problemas teóricos y conocimientos infantiles. Barcelona: Gedisa.

Noel, G. (2006). Una aproximación etnográfica a la cotidianidad, el conflicto y la violencia en escuelas de barrios populares. Miradas interdisciplinarias sobre la violencia en las escuelas. Buenos Aires: Ministerio de Educación, Ciencia y Tecnología de la Nación.

Núñez, P., \& Litichever, L. (2015). Radiografía de la experiencia escolar. Ser joven en la escuela. Buenos Aires: Grupo Editor Universitario, Clacso.

Rawls, J. (1993). Teoría de la justicia. Buenos Aires: Fondo de Cultura Económica.

Roberti, E. (2015). Prácticas laborales juveniles y fragmentación social. La difícil transición de la escuela al trabajo. Buenos Aires: Noveduc.

Stake, R. (1995). Investigación con estudios de caso. Madrid: Morata.

Tedesco, J. C. (2009). Educación y sociedad en la Argentina (1880-1945). Buenos Aires: Solar.

Tenti-Fanfani, E. (2000). Culturas juveniles y cultura escolar. Buenos Aires: Iipe.

Tenti-Fanfani, E. (2006). La condición docente. Buenos Aires: Siglo XXI.

Tiramonti, G. (Comp.) (2004). La trama de la desigualdad educativa. Mutaciones recientes en la escuela media. Buenos Aires: Manantial.

Universidad Nacional de La Plata, \& Liceo Víctor Mercante (2001). Nuestro Liceo. La Plata: UNLP.

Urresti, M. (2000). Paradigmas de participación juvenil: un balance histórico. La participación social y política de los jóvenes en el horizonte del nuevo siglo. Buenos Aires: Clacso.

Van Zanten, A. (2003). Middle Class parents and social mix in french urban schools: Reproduction and transformation of class relations in education? International Studies in Sociology of Education, 13(2), 107-124. 
Van Zanten, A. (2008). ¿El fin de la meritocracia? Cambios recientes en las relaciones de la escuela con el sistema económico, político y social. En E. Tenti-Fanfani (2008). Nuevos temas de la agenda político educativa. Buenos Aires: Siglo XXI.

Viñao-Frago, A. (2002). Sistemas educativos, culturas escolares y reformas. Madrid: Morata.

Young, M. (1961). The rise of the meritocracy, 1870-2033: An essay on education and equality. Baltimore: Penguin Books. 